\title{
Teaching social anthropology in relation to psychiatry
}

\author{
KeITH LloYd, Senior Registrar, Department of Psychological Medicine, King's College \\ Hospital, Denmark Hill, London SE5; SHERIN PeZESHGI, Senior Registrar, \\ Childrens' Department, Maudsley Hospital, London SE5 8AZ; and MATTHEW HoDES, \\ Research Worker, Institute of Psychiatry, De Crespigny Park, London SE5 8AF
}

This article deals with the organisation and evaluation of a pilot series of seminars at the Institute of Psychiatry on the relevance of social anthropology to psychiatry. Despite increasing interest in the relationship of culture to psychiatry, trainees have few opportunities to learn about anthropological issues in psychiatric theory, practice and research. The present authors, all with higher degrees in social anthropology, believe that this is one of the first seminar series of its kind in the country specifically for mental health trainees. Some further possibilities for developing and applying this teaching are also considered.

\section{Background}

It is over 30 years since Aubrey Lewis emphasised the importance to psychiatry of social sciences such as anthropology (Lewis, 1958). Recent years have witnessed the publication of many articles, in the spheres of both physical and psychological medicine, concerned with ethnicity, communication and 'culture'. Current College guidelines for the MRCPsych exam emphasise the importance of cultural variations in social structure, functioning and mental illness (Royal College of Psychiatrists, 1987). Given this interest in the relationship of psychiatry to culture, we were struck by the relative absence from our postgraduate psychiatric training of any teaching on the concepts of social anthropology as they apply to psychiatry. Consequently, we devised a seminar package so that trainees at our postgraduate teaching hospital might be better equipped to evaluate and bring anthropological concepts to bear in their clinical and research practices.

We felt like Krause (1990) that there is a need for improved communication between the social sciences and psychiatry. One common misunderstanding, raised by Leff(1990), is that some of the anthropological criticism of cross-cultural psychiatry can be read as being unconstructively dismissive and lacking in clear thought. We wanted to demonstrate that anthropology is a rigorous social science with a tradition as long as psychiatry and that anthropologists do not necessarily dismiss the epidemiological approach to cross cultural psychiatry. Like Leff, and other workers in the field we wanted to explore the possibilities for constructive collaboration between anthropology and psychiatry.

\section{The seminars}

Our seminars were intended to complement other seminars more concerned with social and epidemiological aspects of psychiatry and less with meanings, values and social organisation.

Our first task was to distil from our anthropological training at the London School of Economics and our subsequent psychiatric experiences, those elements which we considered relevant to psychiatry. We wanted to provide an introduction to the principles of medical anthropology and to examine how such an approach might provide insights into the nature of psychiatric disorder, research and clinical practice. Our emphasis was not on exotic foreign cultures but rather on the essentially reflexive nature of anthropological enquiry. We wanted to suggest that psychiatrists' own beliefs are as legitimate objects of investigation as the beliefs and practices of our patients at home or abroad. Above all we wanted to make our teaching relevant to clinical and research practice hence our chosen title 'Anthropology as applied to Psychiatry'.

As we had only five seminars, we wanted to introduce concepts, illustrate them with appropriate, psychiatrically relevant material and suggest directions for further reading. The first seminar was entitled 'What is Medical Anthropology?' and dealt with the relationship between social anthropology, sociology, and psychiatry. The second seminar was called 'Epidemiology and Ethnograhy' and compared qualitative v. quantitative methodologies and the inter-relationship of culture, translation, interpretation and coherence. Attention was given to Kleinman's accounts of patients' explanatory models of their disorders (Kleinman, 1978). The third seminar, 'Culture Bound Syndromes', attempted to reconcile alternative views of culture as pathogenic or pathoplastic. This considered the relationship between culture, social organisation, and disorders such as anorexia nervosa as well as 'exotic' disorders such as Koro. Seminar four, 'Culture and Treatments' 
considered help seeking behaviour and explanations of treatments. Examples included religious healing as well as the 'rituals' of western psychiatric treatments. The final seminar 'Clinical Applications of Anthropology to Psychiatry' drew together themes from the earlier seminars. The relevance of anthropology to quantitative research settings was also discussed.

\section{Course evaluation}

We sought the opinions of those who attended the seminar series using a simple questionnaire. The seminars were held on a weekly basis with seven people attending, five on a regular basis. Discussion with the organisers of other seminar series indicated that this was a good average attendance for a series of this kind. Each seminar was led by two of the authors. Participants included one medical student, two registrars, one senior registrar and three overseas clinical assistants.

Six of the seven respondents agreed, four of them strongly, that the topics are important and should be taught in all psychiatric training schemes in the UK. One respondent felt that the seminars had "served well to stimulate and provoke thought". Another commented that she felt the issues raised were "particularly relevant to overseas trainees".

\section{Comment}

It would be possible to develop the teaching of social anthropology by considering psychiatric practice in diverse clinical settings along lines suggested by Kleinman (1986) as the impact of cultural patterns of health seeking and illness behaviour are best observed in clinical environments. This teaching could take the form of consultation to or supervision of clinical work by appropriately trained clinicians. Kleinman also suggested that visits to the homes of patients and local healers can be enriched by discussion with anthropologists. A minority of psychiatric trainees will be especially interested in social anthropology and they should be encouraged to obtain a basic training in the discipline. This would enhance their clinical practice and enable them to carry out research at the interface between social anthropology and psychiatry.

Even though there is great pressure on the MRCPsych syllabus it would be possible to include questions on cultural issues in either the multiple choice or short answer sections provided that trainees are taught the basics of the subject. We should ensure that psychiatric trainees have some familiarity with social science, including social anthropology, because these disciplines can shape our practice and provide ways of understanding it.

\section{Acknowledgements}

The author would like to thank Drs C. Kumar and D. Goldberg for their encouragement and support. Matthew Hodes was supported by the Medical Research Council.

\section{References}

Kleinman, A. (1978) Concepts and a model for the comparison of medical systems as cultural systems. Social Science \& Medicine, 12, 85-93.

(1986) Towards a balance in the basic science training of psychiatrists: the place of anthropology in the psychiatric curriculum. WHO workshop in collaboration in psychiatric training. Institute of Psychiatry, 21 to 24 April 1986.

KraUse, I. (1990) Cross-cultural psychiatric research: an anthropologist's view. Psychiatric Bulletin, 14, 143-146.

LEFF, J. (1990) The 'new cross-cultural psychiatry': a case of the baby and the bathwater. British Journal of Psychiatry. 156, 305-307.

LEWIS, A. J. (1958) Social psychiatry in Lectures on the Scientific Basis of Medicine, Vol. VI. London: Athlone Press.

Royal College of Psychiatrists (1987) General information and regulations for the MRCPsych examination, p. 20. London: Greenaway Harrison.

A full list of references and reading material to accompany the course are available on request from Dr Keith Lloyd. 